\title{
ADOKEN: MR İÇİN DERİN ÖĞRENME TABANLI KARAR DESTEK YAZILIMI
}

\author{
Hakan Alp EREN*, Savaş OKYAY, Nihat ADAR
}

Eskișehir Osmangazi Üniversitesi, Mühendislik-Mimarlık Fakültesi, Bilgisayar Mühendisliği Bölümü, Eskișehir, Türkiye

\begin{tabular}{|c|c|}
\hline Anahtar Kelimeler & Öz \\
\hline $\begin{array}{l}\text { Derin Öğrenme, } \\
\text { Nörogörüntüleme, } \\
\text { Yazılım Aracl. }\end{array}$ & $\begin{array}{l}\text { Makine öğrenmesinin alt sınıfı olan derin öğrenme, birden çok katman ile ham } \\
\text { veriden özelliklerin çıkarılmasını sağlamaktadır. Son yllardaki teknolojik } \\
\text { geliş̧meler ile özellikle sağlı alanındaki görüntü işleme çalışmalarında slklıkla } \\
\text { tercih edilmektedir. Başarılı sonuçlar elde etmek için derin öğrenme modellerindeki } \\
\text { parametrelerin optimize edilmesi gerekir. Bu işlemin belli bir düzeyde yazılım } \\
\text { bilgisi gerektirmesi, alana yeterince hâkim olmayan kişilere zorluk } \\
\text { oluşturabilmektedir. Araştırmacılar, kodlama gerektirmemesi nedeniyle hazır derin } \\
\text { öğrenme modellerini ve görsel araçları tercih edebilmektedirler. Bu çalışmada } \\
\text { önerilen uygulama aracıllğıyla, manyetik rezonans görüntüleme taramaları için } \\
\text { kompleks derin öğrenme işlemlerinin doğrudan grafik arayüzü üzerinden } \\
\text { gerçekleştirilmesi hedeflenmektedir. Uygulama; veri seçimi, ön işleme, model } \\
\text { oluşturma, eğitim ve test ana modüllerinden oluşmaktadır. Önde gelen bazı derin } \\
\text { öğrenme modelleri uygulamaya entegre edilmiş olarak sunulmaktadır. İzlenen } \\
\text { uyumluluk tasarımı sayesinde gelecekte yeni mimarilerin de kolaylıkla } \\
\text { eklenebilmesinin önü açılmıştır. Modüller, açı kaynak manyetik rezonans } \\
\text { görüntüleme verisi araçlığıyla doğrulanarakuygulamanıntest tabanlı geliștirilmesi } \\
\text { sağlanmıştır. Fonksiyonellik doğrulama testlerinde üç boyutlu evrişimsel sinir ağı } \\
\text { kullanılarak literatüre paralel şekilde \%81 doğruluk oranı gözlemlenmiştir. } \\
\text { Uygulamanın radyoloji uzmanları ve araştırmacılar gibi kullanıcılar tarafindan } \\
\text { karar destek amacıyla kullanılabileceği düşünülmektedir. }\end{array}$ \\
\hline
\end{tabular}

\section{ADOKEN: DEEP LEARNING BASED DECISION SUPPORT SOFTWARE FOR MRI}

\section{Keywords \\ Deep Learning, \\ Neuroimaging, \\ Software Tool.}

\begin{abstract}
Deep learning, a subclass of machine learning, enables the extraction of features from raw data through multiple layers. With the technological developments in recent years, it is widely preferred in medical image processing studies. Parameters in deep learning models are needed to be optimized to obtain accurate results. This process requires a certain level of software knowledge and can cause difficulties for people who do not have sufficient proficiency. Researchers may prefer readily available deep learning models and visual tools as these do not require coding. It is proposed in this study that users can perform complex deep learning processes for magnetic resonance imaging data directly through the graphical interface of the application. The software tool consists of data selection, pre-processing, model creation, training, and test main modules. Some popular deep learning models are integrated into the application. New model architectures can be easily added for future releases, thanks to the compatibility design. The modules are validated via open-source magnetic resonance imaging data, and in this way, test-driven development is achieved. In the functionality validation tests performed, accuracy rate of $81 \%$ is observed similar to the literature by using three-dimensional convolutional neural network. It is thought that radiology experts and researchers can take advantage of the application for decision support purposes.
\end{abstract}

\footnotetext{
Alıntı / Cite

Eren, H.A., Okyay, S., Adar, N., (2021). Adoken: MR İçin Derin Öğrenme Tabanlı Karar Destek Yazılımı, Mühendislik Bilimleri ve Tasarım Dergisi, 9(2), 406-413.
}

\footnotetext{
* Illgili yazar / Corresponding author: erenhalp@gmail.com, +90-542-380-2697
} 


\begin{tabular}{l|l|l}
\hline Yazar Kimliği / Author ID (ORCID Number) & \multicolumn{3}{|l}{ Makale Süreci / Article Process } \\
\hline H. A. Eren, 0000-0001-6105-158X & Başvuru Tarihi / Submission Date & 06.03 .2021 \\
S. Okyay, 0000-0003-3955-6324 & Revizyon Tarihi / Revision Date & 09.05 .2021 \\
N. Adar, 0000-0002-0555-0701 & Kabul Tarihi / Accepted Date & 10.05 .2021 \\
& Yayım Tarihi / Published Date & 20.06 .2021 \\
\hline
\end{tabular}

\section{Giriş (Introduction)}

Alzheimer hastalığı hafıza, düşünce ve davranışlarla ilgili sorunlara neden olan bir demans türüdür. Semptomlar genellikle yavaşça gelişmekte ve zamanla kötüleşmektedir. Bilinen en büyük risk faktörü artan yaştır ve hastaların çoğunluğu 65 yaş üzeridir. Ancak Alzheimer sadece bir ileri yaş hastalığı değildir. Amerika'da 65 yaş altındaki yaklaşık 200.000 kişi bu hastalığa sahiptir. Hastalığın mevcut bir tedavisi yoktur, fakat semptomlar için tedaviler bulunmaktadır (Alzheimer's Association, 2021). Erken teşhis, hastanın yaşam kalitesinin arttırılmasında oldukça önemli rol oynamaktadır. Gelişen teknoloji ile birlikte günümüzde bu tip hastalıkların tespitinde kullanılmak üzere birçok derin öğrenme çalışması mevcuttur. Donanım alanındaki ilerlemeler sayesinde sağlık alanında kullanılan manyetik rezonans (MR) görüntüleri ev ortamındaki bilgisayarlarda bile işlenebilmektedir.

Alzheimer ile ilgili yapılan nörogörüntüleme çalışmalarına bakıldığında; Payan ve Montana (2015) derin öğrenme yöntemleri ile Alzheimer hastalığının tahmini üzerine Alzheimer's Disease Neuroimaging Initiative (ADNI) veri setini kullanarak bir çalışma yapmışlardır. İki boyutlu ve üç boyutlu evrişimsel sinir ağları (CNN) kullanılarak oluşturulan modellerde sırasıyla \%85,53 ve \%89,47 başarı elde edilmiştir. Nalçakan (2018) tarafından önerilen modelde ise ADNI veri seti ve üç boyutlu evrişimsel sinir ağı mimarisi ile \%90,6 doğruluk oranına ulaşılmıştır. Liu vd. (2018) yaptıkları çalışmada evrişimsel sinir ağı ve tekrarlayan sinir ağlarını kullanarak üç boyutlu pozitron emisyon tomografi (FDG-PET) görüntüleri ile \%91,2 doğruluk oranı elde etmişlerdir. Feng vd. (2019) tarafından gerçekleștirilen çalışmada evrişimsel sinir ağı ve uzun kısa süreli bellek (LSTM) yöntemleri Alzheimer hastalığının tespitinde kullanılarak \%94,82 başarı oranı elde edilmiştir.

Literatürdeki benzer çalıșmalar incelendiğinde bazı araștırmacıların, kodlama bilgisi gerektirmemesi nedeniyle hazır derin öğrenme modellerini kullandıkları görülmektedir. Gerçekleștirilecek kompleks derin öğrenme işlemleri için çeșitli görsel araçlara ihtiyaç duyulmaktadır. Makine öğrenmesi alanındaki görsel araçlara verilebilecek en iyi örneklerden biri olan Waikato Environment for Knowledge Analysis (WEKA), araştırmacıların makine öğrenmesindeki en son tekniklere kolay erişimini sağlayacak birleşik bir çalışma ortamına yönelik algılanan ihtiyaçla ortaya çıkmıştır ve bir dönüm noktası olarak kabul edilerek, akademi ve iş dünyasında yaygın olarak kullanılmaktadır (Hall vd., 2009). Günümüzde derin öğrenme alanında da benzer uygulamalara rastlamak mümkündür. NVIDIA tarafından geliștirilmiş Deep Learning GPU Training System (Yeager vd., 2015), derin öğrenme işlemlerinin arayüz kullanılarak yapılmasına olanak sağlama amacıyla ortaya çıkmıştır. Fakat spesifik alanlarda daha özelleşmiş uygulamalara ihtiyaç duyulmaktadır. Von Chamier vd. (2020) biyogörüntülemede derin öğrenmeyi kullanmak için gereken kaynakların ve uzmanlığın, çoğu laboratuvar için önemli engeller olduğunun altını çizmektedirler. Çözüm olarak kullanıcıların segmentasyon, gürültüden arındırma benzeri işlemleri yapabilmesi için derin öğrenme ağlarını kullanmasını sağlayan ZeroCostDL4Mic platformunu sunmuşlardır. Klemm vd. (2018), Barista aracı ile grafik arayüz sayesinde kullanıcı tarafından derin öğrenme ağ mimarisinin düzenlenebilmesine ve eğitilebilmesine olanak sağlamışlardır. Arnold (2017) kerasR çalışmasında derin öğrenmede en çok kullanılan kütüphanelerden biri olan Keras için $R$ ile bir arayüz geliștirmiștir. Bir bașka çalışmada Lang vd. (2019) tarafından geliştirilen WekaDeeplearning4j ile WEKA aracılığıyla kullanıcıların kod yazmalarına gerek kalmadan derin öğrenme işlemlerine ulaşabilmesi sağlanmıştır. Benzer şekilde Akundi (2018) öğrencilerin derin öğrenme kavramını anlamasına yardımcı olması için MNIST veri seti ile MATLAB üzerinde bir derin öğrenme kullanıcı arayüzü uygulaması geliştirmiştir. Sağlık alanında da kullanılmak üzere çalışmalar bulunmaktadır. Örneğin, Milde vd. (2018) tarafından geliștirilmiş uygulama ile Digital Imaging and Communications in Medicine (DICOM) formatındaki MR görüntülerini inceleme, ön işleme ve ağ eğitme mümkündür. Bucholc vd. (2019) geliştirmiş oldukları klinik destek sistemini ADNI veri seti aracılığıyla doğrulamışlardır. Bu çalıșmada ön ișleme, makine öğrenmesi algoritmalarından model olușturma ve doğrulama yöntemlerine yer vermişlerdir. Rubasinghe ve Meedeniya (2020) tarafından önerilen nörobilim karar destek sisteminde ise hem makine öğrenmesi, hem de derin öğrenme algoritmaları kullanılmıştır. Sistem içerisinde ayrıca ön işleme ve doğrulama yöntemleri uygulanabilmektedir.

Bu çalışmada önerilen uygulama† ile birlikte kullanıcıların, kodlama bilgisi olmadan da, sade bir arayüz yardımıyla derin öğrenme modeli eğitip kullanabilmeleri hedeflenmektedir. MR görüntülerinden oluşan veri seti kullanarak kullanıcı arayüzü yardımıyla eğitilen modeller aracılığıyla demans hastalık tespitinin gerçekleştirilmesi sağlanmaktadır. Doktorlar ya da bireysel olarak kendi sonucunu değerlendirmek isteyen kişilerin sonuçlarını

\footnotetext{
${ }^{\dagger}$ Açık kaynak olarak geliştirilen projeye https://github.com/haeren/adoken adresinden erişilebilmektedir.
} 
arayüz yardımıyla değerlendirirken, radyoloji uzmanlarının da iş yükünün azalması öngörülmektedir. Ayrıca beyin MR görüntüleri ile çalışırken önemli bir ön işleme adımı olan beyin harici kısımların görüntüden çıkarılması (skull stripping) vb. işlemler için FreeSurfer (Fischl, 2012) gibi çeşitli programlar kullanılmaktadır. Bu işlem, geliştirilen uygulamaya entegre edilen DeepBrain (Itzcovich, 2018) kütüphanesi sayesinde başka bir programa ihtiyaç duymadan gerçekleştirilebilmektedir. Ek olarak MR görüntüleri üzerinde normalizasyon gerçekleştirmek için intensity-normalization (Reinhold vd., 2019) kütüphanesindeki z-skor normalizasyon fonksiyonuna uygulama içerisinden doğrudan erişilebilmektedir. Önerilen uygulamanın özellikle nörogörüntüleme alanında çalışan kişilere katkı sağlayacağı düşünülmektedir. Literatüre sunulan karar destek sistemi, mevcut uygulamalar ile Tablo 1'de karşılaştırılmıştır.

Tablo 1. Diğer Uygulamalar ile Karșlaștırma (Comparision with Other Applications)

\begin{tabular}{|c|c|c|c|c|c|}
\hline & $\begin{array}{c}\text { FreeSurfer } \\
\mathbf{( 2 0 1 2 )}\end{array}$ & $\begin{array}{c}\text { Milde vd. } \\
\mathbf{( 2 0 1 8 )}\end{array}$ & $\begin{array}{c}\text { Bucholc vd. } \\
\mathbf{( 2 0 1 9 )}\end{array}$ & $\begin{array}{c}\text { Rubasinghe } \\
\text { ve } \\
\text { Meedeniya } \\
\text { (2020) }\end{array}$ & $\begin{array}{c}\text { Geliştirilen } \\
\text { uygulama }\end{array}$ \\
\hline $\begin{array}{c}\text { MR görüntüsünü yeniden } \\
\text { örnekleme }\end{array}$ & $\sqrt{ }$ & $\sqrt{ }$ & $\sqrt{ }$ & $\sqrt{ }$ \\
\hline $\begin{array}{c}\text { Beyin harici kısımların } \\
\text { görüntüden çlkartılması }\end{array}$ & $\sqrt{ }$ & & & $\sqrt{ }$ & $\sqrt{ }$ \\
\hline $\begin{array}{c}\text { MR görüntülerini normalize } \\
\text { etme }\end{array}$ & $\sqrt{ }$ & $\sqrt{ }$ & $\sqrt{ }$ & $\sqrt{ }$ \\
\hline Derin öğrenme & & $\sqrt{ }$ & $\sqrt{ }$ & $\sqrt{ }$ \\
\hline
\end{tabular}

İlerleyen bölümde öncelikle kullanılan materyal ve sistem tasarımı hakkında bilgi verilmekte olup, uygulama içerisindeki modüllerin işlevleri açıklanmakta ve arayüz tasarımları gösterilmektedir. Üçüncü bölümde gerçekleștirilmiş olan fonksiyonellik testleri ve doğrulama sonuçları verilmiştir. Dördüncü bölümde sonuç ve uygulamaya eklenebilecek özelliklerden bahsedilmektedir.

\section{Materyal ve Yöntem (Material and Method)}

Bu çalışmada önerilen sistem içerisindeki modüllerin geliştirilmesi için Python 3.6 dilinden faydalanılmıştır. Veri ön işleme yöntemleri olarak yeniden örnekleme, beyin harici kısımların görüntüden çlkarılması ve z-skor normalizasyon bulunmaktadır. Model oluştururken seçilmesi gereken derin öğrenme mimarilerine 3D CNN ve 2D CNN-LSTM entegre edilmiştir. Uygulama, The Neuroimaging Informatics Technology Initiative (NIfTI) formatındaki “.nii" uzantılı dosyalar ile uyumludur. Hastalara ait MR görüntüleri, bu dosyalar içerisinde saklanmaktadır. İki boyutlu dilimlerden oluşan bu görüntüler, üç boyutlu bir dizi oluşturmaktadırlar. NIfTI dosyaları sisteme yüklenerek, üç boyutlu diziler üzerinde çeşitli işlemlerin gerçekleştirilmesi sağlanmaktadır. Bu işlemlerin kategorileri baz alınarak ana modüller oluşturulmuştur. Modüller alt parçalara ayrılmış ve ADNIveri seti ile doğrulanarak test tabanlı bir geliştirme sürecinin izlenmesi sağlanmıştır. Modüllerin kullanıcıya sunduğu işlemlerin gerçekleştirilebilmesi için sisteme bazı parametrelerin verilmesi gerekmektedir. Sistem, verilen parametreler doğrultusunda belirtilen işlemleri yaparak kullanıcıya çıktı vermektedir. Kullanıcı ve sistem arasında alışverişi gerçekleșen veriler Şekil 1'de özetlenmektedir.

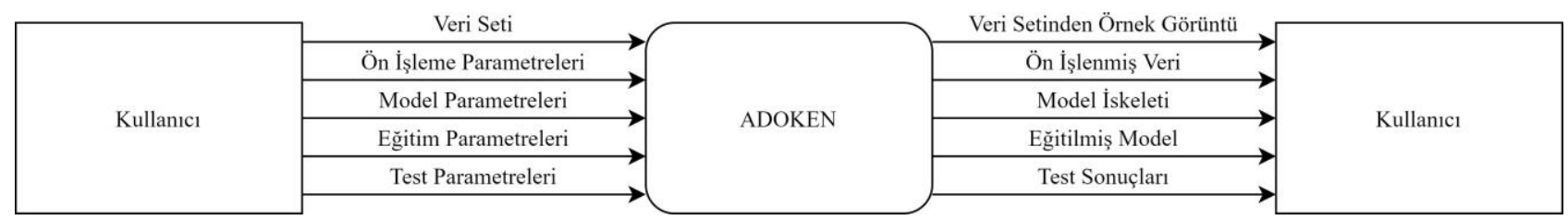

Şekil 1. Kavramsal Veri Akış Şeması (Conceptual Data Flow Diagram)

\subsection{Sistem Tasarımı (System Design)}

Geliştirilen sistem çeşitli yazılımsal ve donanımsal bileşenlerden oluşmaktadır. Kullanıcı, $Q t$ aracılı̆̆ıyla oluşturulmuş kullanıcı dostu arayüzü kullanarak seçimler yapabilmektedir. Bu seçimler PyQt aracılığıyla Python kodu içerisinde algılanmaktadır. Kullanıcının arayüze girdiği bilgiler doğrultusunda Keras ile derin öğrenme modelleri üzerinde işlemler gerçekleşmektedir. Keras, derin öğrenme modelleri üzerinde yüksek seviyeli işlemlerin gerçekleştirilmesini sağlayan Python dilinde yazılmış model düzeyinde bir API'dır. Ancak gerçekleştirilecek düşük seviyeli işlemler için arka uç tarafında kullanabileceği bir tensör manipülasyon kütüphanesine ihtiyaç duymaktadır (Chollet, 2018). Google tarafından geliştirilen tensör manipülasyon çerçevesi olan Tensorflow bu aşamada devreye girmektedir. Bu bileşenler arasındaki ilişki Şekil 2(a)'da gösterilmektedir. 
Ayrıca derin öğrenmede kullanılan hesaplamaların hızlandırılması için CUDA Deep Neural Network Library $(c u D N N)$ tercih edilmektedir. Compute Unified Device Architecture (CUDA), matematiksel hesaplamaların GPU üzerinde paralel bir şekilde yapılmasını sağlayarak sisteme hız kazandırmaktadır. GPU ile bağlantının sağlandığı bileşenler Şekil 2(b)'de verilmektedir.
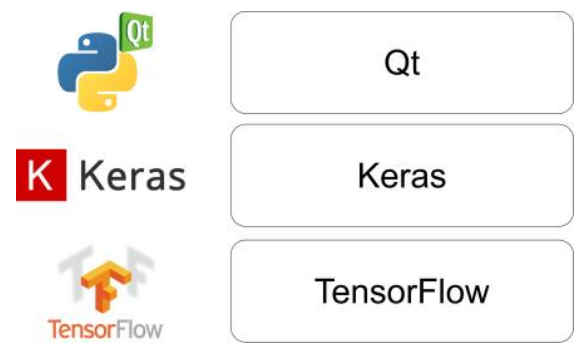

(a)

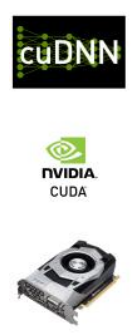

Şekil 2. Yazılımsal ve Donanımsal Bileşenler (Software and Hardware Components)

Uygulama, gerçekleştirilen işlemlerin türüne göre veri seçimi, veri ön işleme, model oluşturma, model eğitimi ve test adındaki modüllere ayrılmaktadır. Veri seçimi modülü ile üzerinde çalışılacak verinin alt setlere ayrılması ve dosya yolunun sisteme gösterilmesi sağlanmaktadır. Veri ön işleme modülüyle birlikte MR görüntülerinde beyin olmayan kısımları çıkarma, yeniden örnekleme ve z-skor normalizasyon uygulanabilmektedir. Model oluşturma modülünde, derin öğrenme mimarisinin ve ilgili parametrelerin belirtilmesi gerekmektedir. Veri seti ve model ile ilgili aşamalar tamamlandıktan sonra eğitim ve test gerçekleştirilebilmektedir. Uygulamadaki adımların özeti ve ait oldukları modüller Şekil 3'te gösterilmektedir.

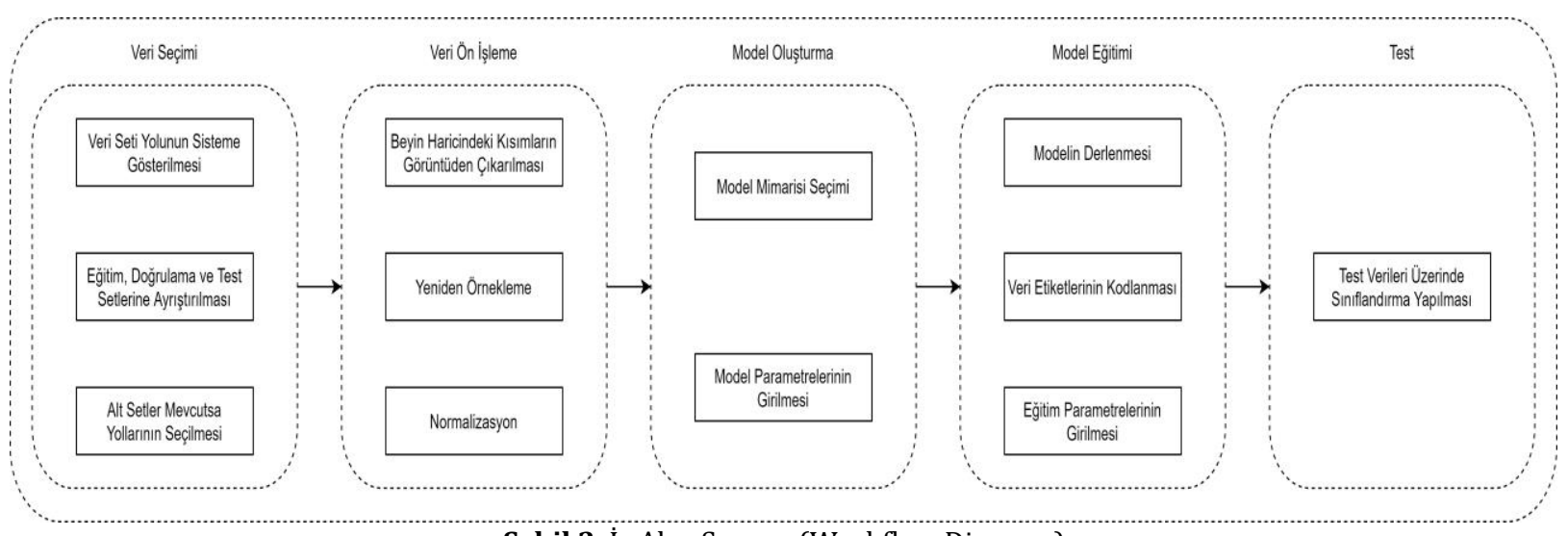

Şekil 3. İş Akış Şeması (Workflow Diagram)

\subsection{Kullanıcı Arayüzü Tasarımı (User Interface Design)}

Kullanıcı arayüzü, sistem tasarımında bulunan modülleri içeren sekmelerden oluşmaktadır. İlk sekme olan veri seçim modülünde dosyanın bulunduğu yolun sisteme gösterilmesi amaçlanmaktadır. Kullanıcı, elinde bulunan veri setini eğitim, doğrulama ve test setlerine ayırabilmektedir. Bu işlem için istenilen alt setlerin oranları sisteme verilmelidir. Ayrıca tercihe bağlı olarak alt setlere ayırma sırasında veri setini karıştırma seçeneği bulunmaktadır. Eğer bu alt setler kullanıcıda hazır olarak bulunuyorsa, direkt olarak bu setlerin yolu da sisteme gösterilebilmektedir. Veri seti seçim modülü Şekil 4(a)'da verilmektedir. İkinci sekme olan veri ön işleme modülünde bulunan fonksiyonlar ile MR görüntülerinin eğitime hazır hale getirilmesi sağlanmaktadır. Kullanıcının ilk olarak hangi veri seti (eğitim, doğrulama, test) üzerinde işlem yapacağını seçmesi gerekmektedir. Belirtilen seçenekte geçerli bir veri yok ise kullanıcı sistem tarafından uyarılmaktadır. Geçerli verinin olduğu durumlarda, veri seti içerisinden örnek bir MR görüntüsü kullanıcıya gösterilmektedir. Uygulama içerisinde hedef oran ve boyut olmak üzere iki farklı yeniden örnekleme seçeneği bulunmaktadır. Hedef boyut seçeneğinde görüntü, belirtilen boyuta sığacak şekilde ayrıca kırpılmakta ve yeniden örnekleme yapılmaktadır. Modelin başarı oranını yükseltmek için görüntüden beyin harici kısımların silinmesi seçeneğini mevcuttur. Ek olarak görüntüler üzerinde z-skor normalizasyon işlemi gerçekleștirilebilmektedir. Veri ön işleme modülü Şekil 4(b)'de gösterilmektedir. 


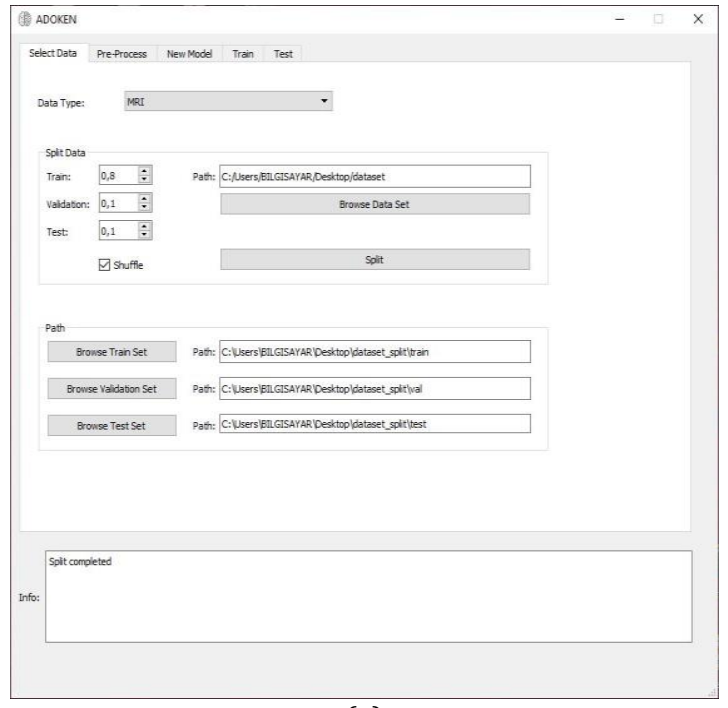

(a)

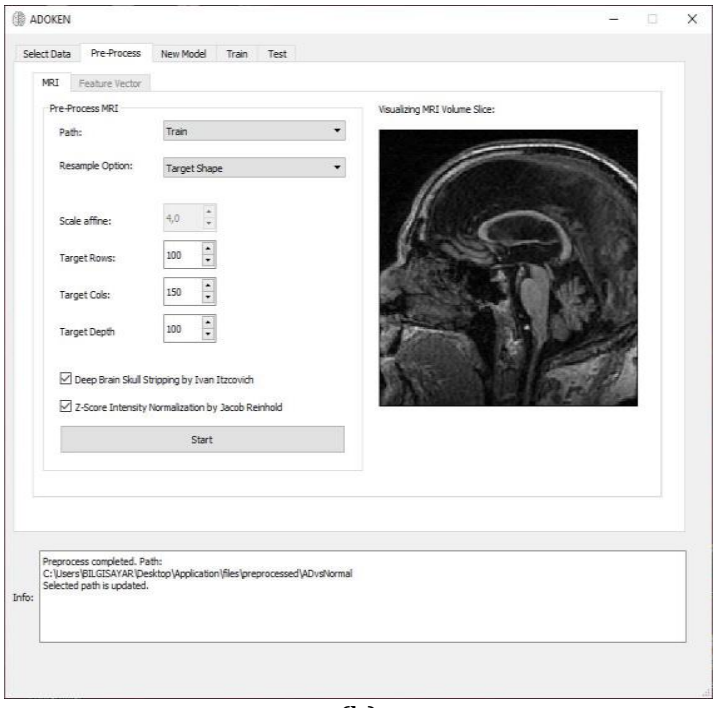

(b)

Şekil 4. Veri Seti Seçim ve Ön İșleme Modülleri (Data Set Selection and Preprocessing Modules)

Üçüncü sekme olan model oluşturma modülünde ilk olarak model mimarisinin seçilmesi gerekmektedir. Uygulama içerisinde 3D CNN ve 2D CNN-LSTM mimarileri entegre edilmiș olarak bulunmaktadır. Modül geliştirmede kullanılan uyumluluk tasarımıyla birlikte ileride başka model mimarilerinin de mevcut sisteme kolay bir şekilde eklenebilmesi sağlanmıştır. Seçilen mimari türüne göre model parametrelerinin değerlerinin girilmesi beklenmektedir. İlk üç parametre MR görüntüsünün bulunduğu üç boyutlu dizinin satır, sütun ve derinlik bilgilerinden oluşmaktadır. Bu parametreler, kullanıcı sisteme geçerli bir veri seti yolu gösterdiğinde otomatik olarak doldurulmaktadır. Filtre parametresi, evrişimdeki çıktı filtrelerinin sayısını ifade etmektedir. Çekirdek boyutu (kernel size) parametresi, evrişim penceresinin uzamsal (spatial) boyutlarını belirtmek için kullanılmaktadır (Chollet, 2018). Evrişim katmanındaki çıktının boyutu, filtrelerin girdi matrisi üzerinde ne kadar aralıkla hareket ettiğine göre değişmektedir. Dolgu (padding) parametresi ile evrişim katmanındaki girdi matrisinin etrafı doldurulabilmektedir. Bu sayede çıktının, girdi matrisi ile aynı boyutta olması sağlanmaktadır. LSTM katmanın model mimarisinde seçilmesi durumunda katmanın çıktı uzayının boyutluluğu, ilgili parametre ile sisteme belirtilmelidir (Chollet, 2018). Aktivasyon parametresi ile model içerisinde kullanılacak aktivasyon fonksiyonunun seçilmesi gerekmektedir. Maksimum havuzlama (max pooling) parametresi ile havuzlama katmanındaki pencerenin büyüklüğü ayarlanmaktadır. Seyreltme (dropout) parametresine girilen oran ile modelin eğitim sırasında așırı uyum göstermesinin (overfitting) önüne geçilmektedir. Son parametre olan sınıf sayısı, modelin tahmin sırasında sınıf olasılıklarını belirleyebilmesi için çıktı katmanında kullanılmaktadır. Parametrelere değerler verildikten sonra model oluşturulabilmekte ve modelin özeti kullanıcıya gösterilmektedir. Model iskeleti, başka eğitimlerde de kullanmak amacıyla JavaScript Object Notation (JSON) formatında kaydedilebilmektedir. Model oluşturma modülü Şekil 5’te verilmektedir.



Şekil 5. Model Oluşturma Modülü (Model Creation Module)

Eğitim modülünde modelin eğitimine başlayabilmek için sistemde modelin ve eğitim/doğrulama verisinin mevcut olması gerekmektedir. Model oluşturma modülünde oluşturulmuş model kullanılabileceği gibi, daha önceden 
oluşturulup kaydedilmiş bir model iskeleti dosyası da bu modül içerisinde sisteme yüklenebilmektedir. Modelin özetine, model oluşturma modülünde olduğu gibi bu modül içerisinde de erişilebilmektedir. Eğitim/doğrulama verisinin sinıflandırmada kullanılabilmesi için etiketlerinin 0 ve 1 şeklinde kodlanması (one hot encoding) gerekmektedir. Bu işlem modül içerisindeki "Eğitim etiketlerini kodla" butonu ile yaplabilmektedir. Kodlama bilgisi, sisteme geri yüklenebilmesi amacıyla NumPy (.npy) formatında ve kullanıcı tarafından okunabilmesi için metin belgesi (.txt) formatında olmak üzere iki farklı uzantı ile kaydedilmektedir. Modelin derlenebilmesi için eniyileștirici (optimizer), kayıp fonksiyonu (loss function) ve model tarafından değerlendirilen metrik parametreleri kullanılmaktadır. Model derlendikten sonra toplu iş boyutu (batch size) ve epok (epoch) parametrelerine değer verilerek eğitim başlatılabilmektedir. Eğitim sırasında doğrulama verisi üzerindeki başarı oranının bir önceki epoktakinden yüksek olması durumunda model otomatik olarak kaydedilmektedir. Bu oran belli sayıda epok boyunca yükselmez ise eğitim durdurulmaktadır. Eğitim tamamlandıktan sonra kullanıcı, modelin en son halini manuel olarak kaydedebilmektedir. Eğitilmiş model, Hierarchical Data Format (.H5) dosyası olarak kaydedilmektedir. Eğitim modülü Şekil 6(a)'da gösterilmektedir. Uygulamadaki son sekme olan test modülünde, bir önceki sekmede eğitilmiș modele ek olarak, $H 5$ formatında saklanan eğitilmiș modeller de sisteme yüklenerek kullanılabilmektedir. Teste başlamadan önce veri etiketlerinin ne şekilde kodlandığının sistem tarafından biliniyor olması gerekmektedir. Eğitim gerçekleştirildiğinde kodlama bilgisi sistemde oluşturulmaktadır. Ancak mevcut oturumda sadece test işlemi gerçekleştirilmek istenirse, kodlama bilgisinin bulunduğu ".npy" uzantılı dosyanın sisteme yüklenmesi gerekmektedir. Test sonuçları modül içerisinde dosya ismi, dosyanın etiketi ve tahmin sonucu şeklinde yazdırılmaktadır. Bu sonuçlar ayrıca Comma Separated Values (CSV) formatında kaydedilmektedir. Sonuçlara ait karmaşıklık matrisi ve bu matristen türeyen performans metriklerinin değerleri de ayrı dosyalar içerisinde saklanmaktadır. Test modülü Şekil 6(b)'de verilmektedir.

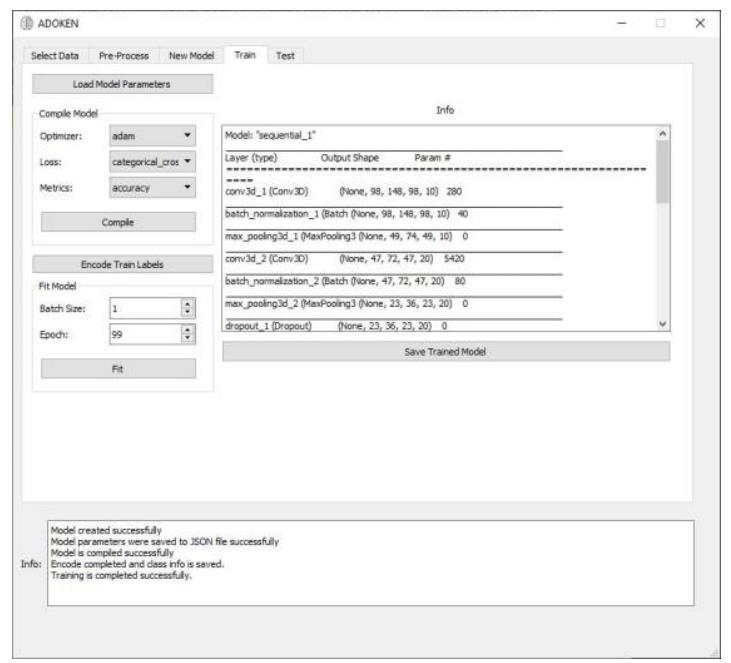

(a)

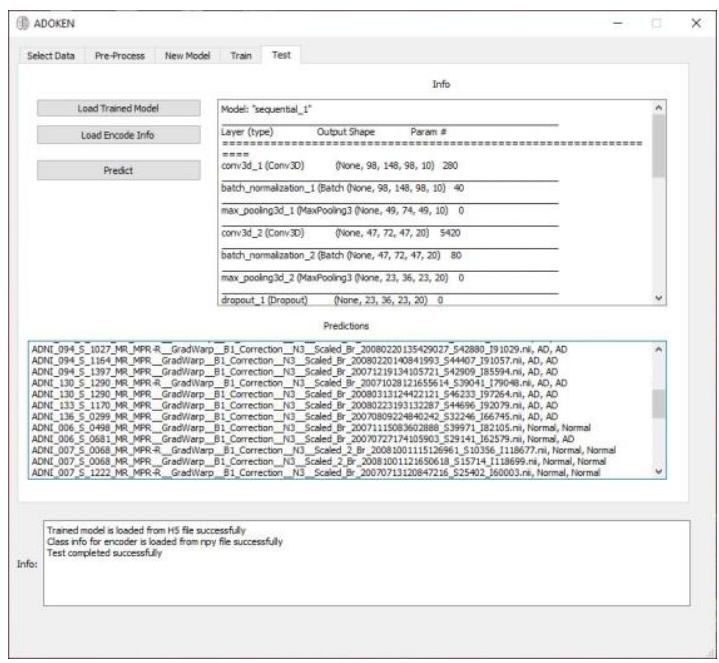

(b)

Şekil 6. Eğitim ve Test Modülleri (Training and Test Modules)

\section{Fonksiyonellik Testleri ve Doğrulama (Functionality Tests and Validation)}

Önerilen yazılımın fonksiyonellik testleri ve örnek sınıflandırma çalıșması popüler ADNI veri seti üzerinde gerçekleștirilmiştir. Bu makalenin hazırlanmasında kullanılan veriler, Alzheimer Hastalığı Nörogörüntüleme Girişimi (ADNI) veri tabanından (adni.loni.usc.edu) elde edilmiştir. ADNI, 2003 yılında Baş Araştırmacı Michael W. Weiner tarafından yönetilen bir kamu özel ortaklığı olarak başlatılmıștır. ADNI'nin birincil amacı, hafif bilişsel bozukluğun (MCI) ve erken dönemdeki Alzheimer hastalığının (AD) ilerlemesini ölçmek için seri manyetik rezonans görüntüleme (MRI), pozitron emisyon tomografisi (PET), diğer biyolojik belirteçler ve klinik ve nöropsikolojik değerlendirmenin birleștirilip birleștirilemeyeceğini test etmektir.

Sistemin geliştirilmesi ve test süreçleri Intel@ Core $^{\mathrm{TM}}$ i3-3220 CPU @ 3.30GHz, 8 GB RAM, NVIDIA GeForce GTX 10502 GB, Windows 10 ve Intel@ Core $^{\mathrm{TM}}$ i7-6700HQ CPU @ 2.60GHz, 12 GB RAM, NVIDIA GeForce GTX $950 \mathrm{M} 2$ GB, Windows 10 konfigürasyonlarına sahip iki bilgisayar üzerinde gerçekleștirilmiştir. Uygulamadaki derin öğrenme fonksiyonlarının çalışabilmesi için CUDA ile uyumlu bir NVIDIA grafik işlemciye sahip olunması gerekmektedir.

Uygulamanın doğrulanması için Alzheimer ve sağlıklı etiketli örnekler ile iki sınıf üzerinden eğitilen modelde üç boyutlu evrişimsel sinir ağ mimarisi test edilmiştir. Oluşturulan model iskeletindeki örnek parametreler Şekil $7(a)$ 'da verilmektedir. Modelin eğitimi ADNI veri setindeki MR görüntüleri üzerinde gerçekleştirilmiştir. Eğitimde kullanılan parametrelere verilen değerler Şekil 7(b)'de gösterilmektedir. 


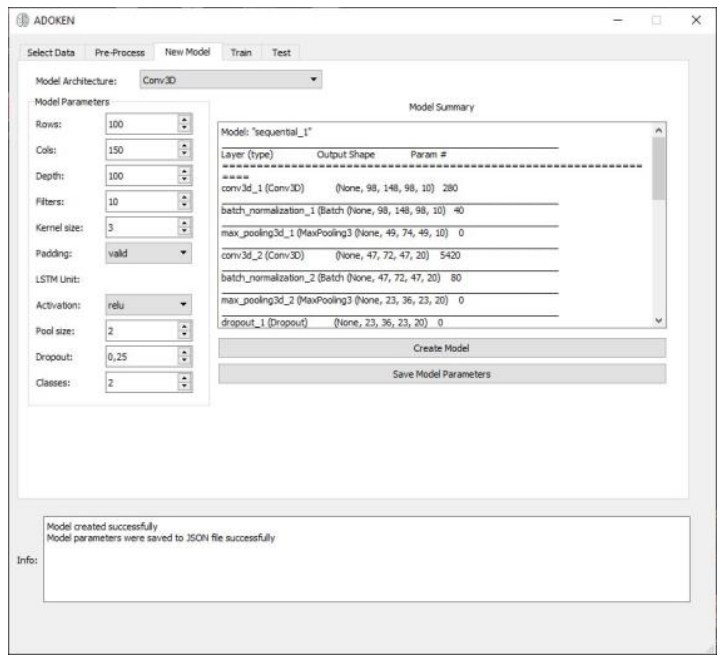

(a)

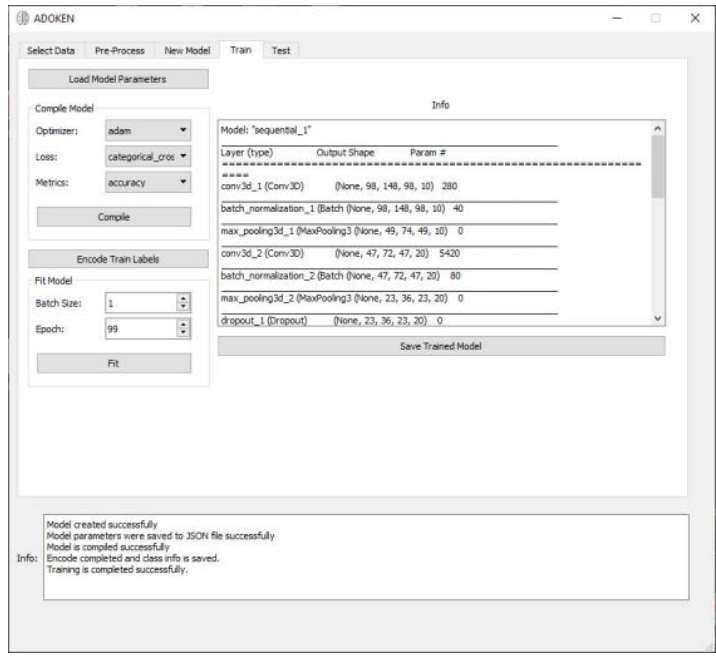

(b)

Şekil 7. Doğrulamada Kullanılan Model ve Eğitim Parametreleri (Model and Training Parameters Used in Validation)

Daha güvenilir bir sonuç elde edebilmek için 10-katlı çapraz geçerlilik (10-fold cross-validation) uygulanmıştır. Doğrulama verisi üzerinde yapılan testlerde literatürdekine benzer şekilde (Jo vd., 2019; Noor vd. 2020; Yamanakkanavar vd., 2020) \%81 doğruluk oranı elde edilmiştir. Uygulanan çapraz geçerlilik testlerindeki örnek bir test işlemine ait sonuçlar Şekil 8(a)'da verilmektedir. Sonuçlara ait performans metrikleri ve bu metriklerin türetildiği karmaşıklık matrisi çıktı dosyaları şeklinde dışarı aktarılmaktadır. Bu dosyaların içeriklerine ait ekran görüntüleri Şekil 8(b)'de gösterilmektedir.

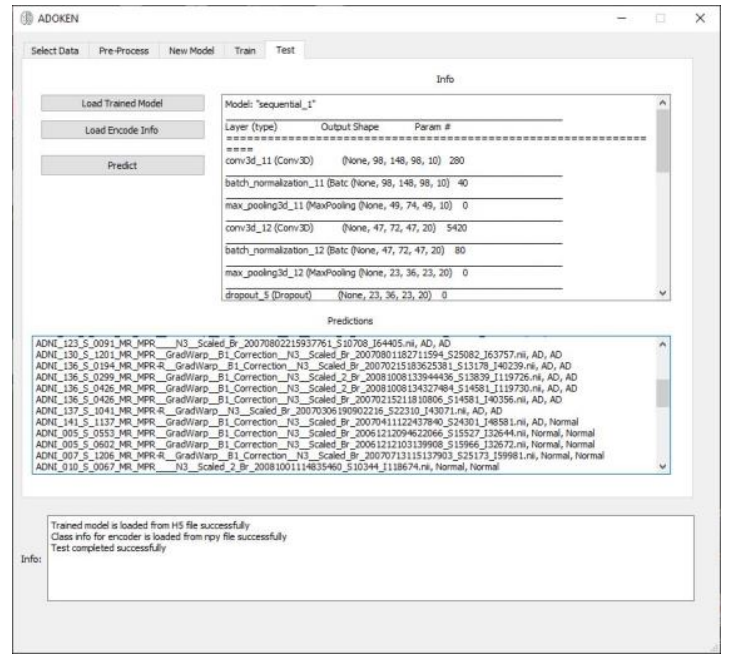

(a)

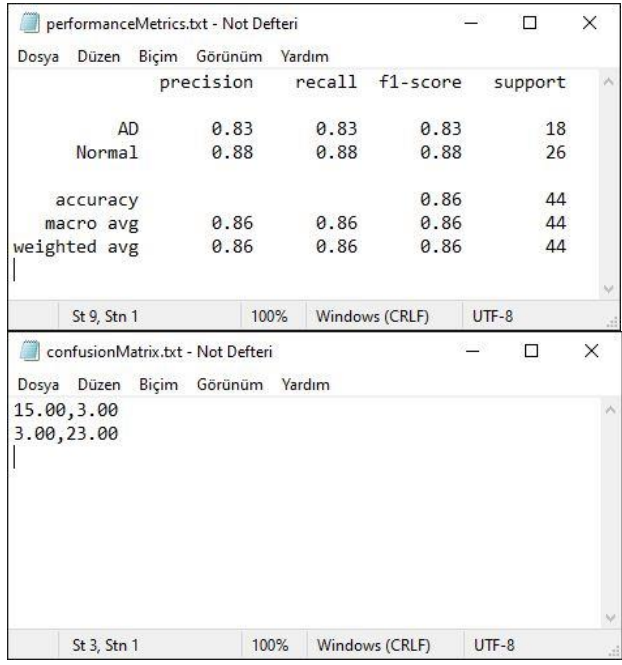

(b)

Şekil 8. Doğrulama Sonuçları ve Performans Metrikleri (Validation Results and Performance Metrics)

\section{Sonuç ve Tartışma (Result and Discussion)}

Literatüre sunulan uygulamanın araştırmacı, doktor, hasta gibi farklı gruptaki kişilere faydalı olacağı öngörülmektedir. Radyoloji uzmanlarının hastaya ait görüntüleri yorumlaması için günler sonrasına randevu verilmektedir. Bu sistem ile birlikte MR çekildiği anda doktorun bir ön fikir edinmesinin sağlanması hedeflenmektedir. Görüntüleri yorumlamada geçen zamandan tasarruf sağlanarak iş yükünün azaltılması ve etkili bir zaman yönetiminin yapılmasının sağlanması planlanmaktadır. Bu sayede gerekli durumlarda hızlı önlemler alınarak hastanın yaşam kalitesinin arttırılmasına yardımcı olunacağı düşünülmektedir. Sonuçların literatürdeki çalıșmalara benzer ve kıyaslanabilir olușu bu yazılımın uzun vadede özellikle akademik çalıșmalardaki testler için uygun bir platform olduğunu doğrulamaktadır. Ayrıca programın istenilen alanlarda özelleștirilerek farklı konularda çalışmalar yapan araștırmacılara ve akademisyenlere de katkı sağlaması beklenmektedir. Uygulamanın geliştirilme sürecinin gelecekte de farklı planlamalarla devam edeceği öngörülmektedir. Bu planlardan biri sistemin farklı formattaki veri tipleri ile de uyumlu hale getirilmesidir. Bir diğeri ise sistem içerisine entegre edilmiş 3D CNN ve 2D CNN-LSTM model mimarilerin yanına yeni derin öğrenme model mimarilerinin de eklenmesidir. 


\section{Teşekkür (Acknowledgement)}

Data collection and sharing for this project was funded by the Alzheimer's Disease Neuroimaging Initiative (ADNI) (National Institutes of Health Grant U01 AG024904) and DOD ADNI (Department of Defense award number W81XWH-12-2-0012). ADNI is funded by the National Institute on Aging, the National Institute of Biomedical Imaging and Bioengineering, and through generous contributions from the following: AbbVie, Alzheimer's Association; Alzheimer's Drug Discovery Foundation; Araclon Biotech; BioClinica, Inc.; Biogen; Bristol-Myers Squibb Company; CereSpir, Inc.; Cogstate; Eisai Inc.; Elan Pharmaceuticals, Inc.; Eli Lilly and Company; EuroImmun; F. Hoffmann-La Roche Ltd and its affiliated company Genentech, Inc.; Fujirebio; GE Healthcare; IXICO Ltd.; Janssen Alzheimer Immunotherapy Research \& Development, LLC.; Johnson \& Johnson Pharmaceutical Research \& Development LLC.; Lumosity; Lundbeck; Merck \& Co., Inc.; Meso Scale Diagnostics, LLC.; NeuroRx Research; Neurotrack Technologies; Novartis Pharmaceuticals Corporation; Pfizer Inc.; Piramal Imaging; Servier; Takeda Pharmaceutical Company; and Transition Therapeutics. The Canadian Institutes of Health Research is providing funds to support ADNI clinical sites in Canada. Private sector contributions are facilitated by the Foundation for the National Institutes of Health (www.fnih.org). The grantee organization is the Northern California Institute for Research and Education, and the study is coordinated by the Alzheimer's Therapeutic Research Institute at the University of Southern California. ADNI data are disseminated by the Laboratory for Neuro Imaging at the University of Southern California.

\section{Çıkar Çatışması (Conflict of Interest)}

Yazarlar tarafından herhangi bir çıkar çatışması beyan edilmemiştir. No conflict of interest was declared by the authors.

\section{Kaynaklar (References)}

Akundi, A. (2018). A Deep Learning Graphical User Interface Application on MATLAB.

Alzheimer's Association. (2021). What is Alzheimer's Disease?. Çevrimiçi: https://www.alz.org/alzheimers-dementia/what-isalzheimers (Erișim tarihi: 20.01.2021).

Arnold, T. B. (2017). kerasR: R interface to the keras deep learning library. Journal of Open Source Software, 2(14), 296.

Bucholc, M., Ding, X., Wang, H., Glass, D. H., Wang, H., Prasad, G., ... Todd, S. (2019). A practical computerized decision support system for predicting the severity of Alzheimer's disease of an individual. Expert systems with applications, 130, 157-171.

Chollet, F. (2018). Keras: The python deep learning library. Astrophysics Source Code Library, ascl: 1806.1022.

Feng, C., Elazab, A., Yang, P., Wang, T., Zhou, F., Hu, H., . . Lei, B. (2019). Deep learning framework for Alzheimer's disease diagnosis via 3D-CNN and FSBi-LSTM. IEEE Access, 7, 63605-63618.

Fischl, B. (2012). FreeSurfer. Neuroimage, 62(2), 774-781.

Hall, M., Frank, E., Holmes, G., Pfahringer, B., Reutemann, P., \& Witten, I. H. (2009). The WEKA data mining software: an update. ACM SIGKDD explorations newsletter, 11(1), 10-18.

Itzcovich, I. (2018). DeepBrain. Çevrimiçi: https://github.com/iitzco/deepbrain (Erişim tarihi: 15.03.2020).

Jo, T., Nho, K., \& Saykin, A. J. (2019). Deep learning in Alzheimer's disease: diagnostic classification and prognostic prediction using neuroimaging data. Frontiers in aging neuroscience, 11, 220.

Klemm, S., Scherzinger, A., Drees, D., \& Jiang, X. (2018). Barista-a graphical tool for designing and training deep neural networks. arXiv preprint arXiv:1802.04626.

Lang, S., Bravo-Marquez, F., Beckham, C., Hall, M., \& Frank, E. (2019). Wekadeeplearning4j: A deep learning package for weka based on deeplearning4j. Knowledge-Based Systems, 178, 48-50.

Liu, M., Cheng, D., Yan, W., \& Alzheimer's Disease Neuroimaging Initiative. (2018). Classification of Alzheimer's disease by combination of convolutional and recurrent neural networks using FDG-PET images. Frontiers in neuroinformatics, 12, 35.

Milde, S., Liebgott, A., Wu, Z., Feng, W., Yang, J., Mauch, L., Gatidis, S. (2018). Graphical User Interface for Medical Deep LearningApplication to Magnetic Resonance Imaging. Paper presented at the 2018 Asia-Pacific Signal and Information Processing Association Annual Summit and Conference (APSIPA ASC).

Nalçakan, Y. (2018). Derin Öğrenme ile Alzheimer Hastalığının Teșhisi. (Yüksek Lisans). İstanbul Üniversitesi-Cerrahpaşa Lisansüstü Eğitim Enstitüsü, İstanbul.

Noor, M. B. T., Zenia, N. Z., Kaiser, M. S., Al Mamun, S., \& Mahmud, M. (2020). Application of deep learning in detecting neurological disorders from magnetic resonance images: a survey on the detection of Alzheimer's disease, Parkinson's disease and schizophrenia. Brain informatics, 7(1), 1-21.

Payan, A., \& Montana, G. (2015). Predicting Alzheimer's disease: a neuroimaging study with 3D convolutional neural networks. arXiv preprint arXiv:1502.02506.

Reinhold, J. C., Dewey, B. E., Carass, A., \& Prince, J. L. (2019). Evaluating the impact of intensity normalization on MR image synthesis. Paper presented at the Medical Imaging 2019: Image Processing.

Rubasinghe, I., \& Meedeniya, D. (2020). Automated neuroscience decision support framework. In Deep Learning Techniques for Biomedical and Health Informatics (pp. 305-326): Elsevier.

Von Chamier, L., Jukkala, J., Spahn, C., Lerche, M., Hernández-Pérez, S., Mattila, P., Krull, A. (2020). ZeroCostDL4Mic: an open platform to simplify access and use of Deep-Learning in Microscopy. BioRxiv.

Yamanakkanavar, N., Choi, J. Y., \& Lee, B. (2020). MRI segmentation and classification of human brain using deep learning for diagnosis of alzheimer's disease: a survey. Sensors, 20(11), 3243.

Yeager, L., Bernauer, J., Gray, A., \& Houston, M. (2015). Digits: the deep learning gpu training system. Paper presented at the ICML 2015 AutoML Workshop. 